\title{
Food habits of the majority: evolution of the current UK pattern
}

\section{By Jane E. Thomas, Department of Nutrition, Queen Elizabeth College, University of London, Campden Hill, London W8 ${ }_{7} A H$}

In recent years nutritionists have focused attention on the food habits of various groups of newcomers to the UK, considering particularly those traditional practices which may put the individual at risk in the new environment. In addition, social nutrition research has focused on the mechanisms behind changing habits amongst both the indigenous population and newer arrivals, for in both cases, as Wenkam \& Wolff ( 1970 ) put it "people no longer grow up and die where they were born, in this highly mobile age people no longer follow the socio-cultural pattern of their parents, adults live in a world which did not exist when they were children, a world shaped by new technologies and new knowledge'.

In examining such interactions between any mobile group and their new hosts it is clearly essential to establish some baseline with regard to the food culture which they are entering. Since this is also likely to be a changing scene the underlying trends must also be considered. Anderson \& Anderson (1969) coined the term 'ethnohoptology' to describe the ways in which a particular group of people relate to food; selection, preparation and consumption patterns. These authors suggested that studies of these phenomena would also provide valuable insight into how a particular culture functioned in a much broader sense. Perhaps this is something we should keep in mind as we look at current UK dietary patterns, since these broader social considerations may be crucial in determining the degree of adjustment required from newcomers to become functioning members of this society. This paper seeks to consider the broad pattern of food habits in the UK and the role of various factors in shaping the current picture. Consideration of the factors associated with variations in the pattern may perhaps provide the sort of clues to social mechanisms referred to by Anderson \& Anderson (I 969).

\section{Breakfast and related items}

Although the emphasis on the importance of particular meals may have changed, the UK is still predominantly a country of three meals a day with snacks. It is the minority, 22\% (Health Education Council, 1979) who never eat breakfast on any day of the week, while $59 \%$ claim to eat breakfast every weekday. This value climbs to $63 \%$ at weekends which suggests that available time on working days may be an important factor. Certainly, that seems to be the case amongst women, since fewer women who work at home $(9 \%)$ miss breakfast than women who go out to work (2 I\%) (Kraft, I978). In addition, there seem to be differences between members of different social groups, in relation both to social class and region of the country (see Fig. I). 


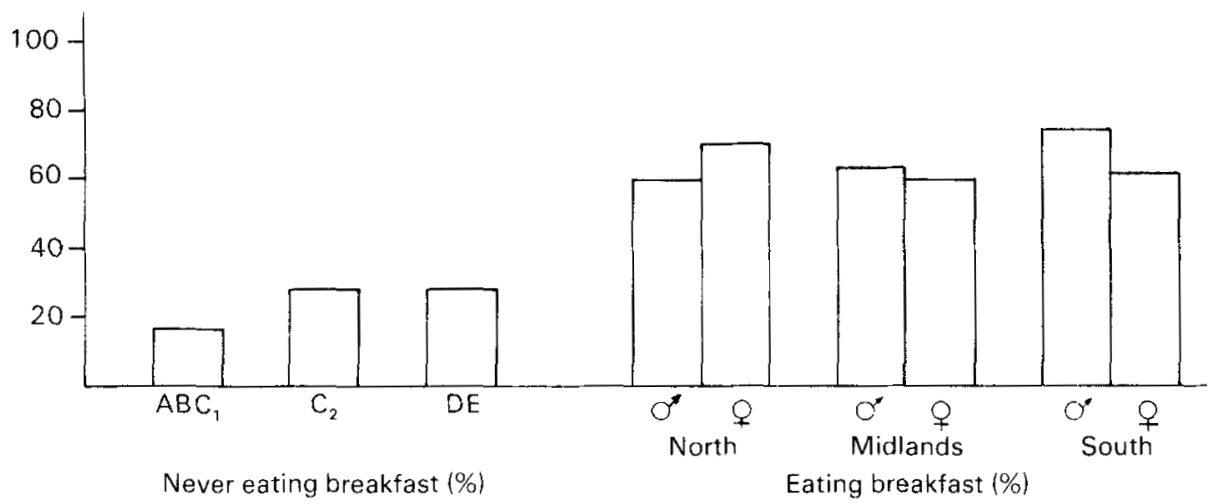

Fig. I. Social and regional variations in patterns of breakfasting in the UK (Kraft, 1978; Health Education Council, 1979).

When considering the foods eaten for breakfast there are again differences between the sexes, social classes and areas of the country. Of those who eat breakfast, $48 \%$ of men claimed to have a cooked breakfast compared with $33 \%$ of women. The proportion of cooked breakfast eaters tends also to be higher in the south than the Midlands or north. Cereals seem to be equally popular with men and women but seem to be less frequently mentioned by the respondents coming from the south in this survey (Kraft, 1978). However, this picture differs somewhat from that presented by National Food Survey data (Ministry of Agriculture, Fisheries and Food, $198 \mathrm{r}$ ), even when oatmeal consumption is included (in order to allow for the possibility that scotland and the northern part of the country may have been misrepresented because of the inclusion of porridge of the 'non-instant' variety under a separate classification from other breakfast cereals). (See Fig. 2).

The higher consumption of oatmeal in northern parts of England and Scotland represents the continuation of a very old tradition, originally supported by factors of availability and the food preferences of early immigrant groups. Oats appear to have reached Britain in the pre-Roman Iron Age and proved an economic crop in

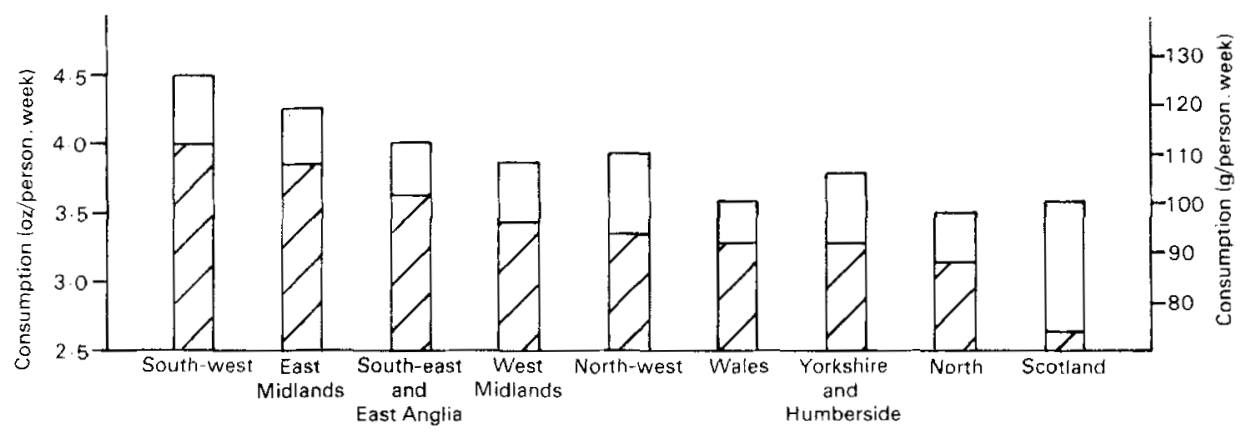

Fig. 2. Regional consumption of breakfast cereal (W) and oatmeal $(\square)$ in the UK (Ministry of Agriculture, Fisheries and Food, 1981). 
the cold wet upland parts of the country where no other cereal would survive. The descendants of Germanic tribes in these areas traditionally raised them to eat in the form of porridge and they also provided valuable fodder for the horses of the Roman cavalry which was active in the same areas. In Britain, pottage, based on oatmeal, remained popular at every level of society throughout the medieval period. The 'brochan' of Scotland was oatmeal porridge with milk. Pennine dalesmen ate oatmeal porridge and in Wales and the south oatmeal was a favourite thickener in many recipes.

By the arrival of the Tudor period cereal pottages tended to be breakfast or supper dishes, and remained a breakfast item amongst all classes until late in the i 7 th century. Thereafter the well-to-do adopted a lighter breakfast of spiced bread or cake with coffee or chocolate. Country people continued for some decades to enjoy cereal pottages at breakfast and the custom survived in northern Britain long after it had been dropped in the south. The role of oatmeal as a thickener in the south was taken over by the roux, an idea which arrived from France in the $17^{\text {th }}$ century. Dr Edward Smith in his dietary surveys, 1862-63 (Barker et al. 1970), found that consumption of oatmeal was more or less restricted to the north-west. It provided only i $\%$ of the total energy intake of the Lancashire cotton workers' normal diet. In marked contrast, Scottish labourers at that time were reported to eat as much as $10-16$ ounces $\left(280-45^{\circ} \mathrm{g}\right.$ ) (raw weight) per meal (Barker et al. 1970).

Bains et al. ( $\left.1_{9} 6_{3}\right)$ discussing the findings of the Rowett Research Institute survey (r937-39) pointed out that the most pronounced difference between the diets of Scotland and England was in oatmeal; Scottish families with one child consuming over twenty times as much as their English counterparts and those with six or more children about six times as much.

What of the post-war trends? The picture appears to be one of a gradual approach to the UK average (see Fig. 3). In general over that period consumption

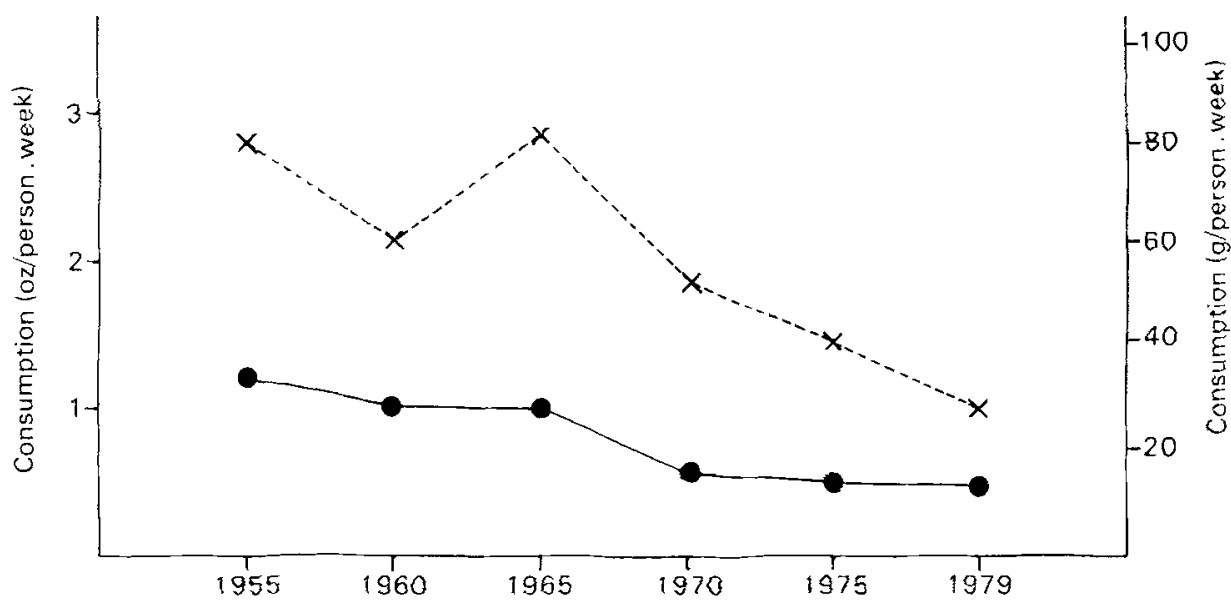

Fig. 3. Consumption of oatmeal (1955-1979) in Scoltish (-- ) and all UK households (-) (Ministry of Agriculture, Fisheries and Food, 1981). 
of cereals such as oatmeal was declining and the strong regional difference was being eroded. The story of oatmeal reflects a number of interesting aspects of social influences on eating habits. Firstly, the most basic of all factors, availability - oatmeal survived in a climate where other cereals did not. Its wider popularity was based on its ability to fill a very specific niche, that of a thickener. However, Britain has always been a country where crops, food and styles of cooking have been accepted from overseas and the arrival from France of the roux for thickening sauces no doubt contributed to the reduction in oatmeal usage in the south. Although it may be unpopular to say so, this also demonstrates the more general trend for older patterns to be abandoned more rapidly in the south while they continue in more isolated parts of the country and amongst less affluent groups. In the post-war period, consumption of this foodstuff also illustrates the trend away from cereal consumption so widely deplored in recent years by nutritionists while against this background we also see another common pattern, the reduction in regional differences. In common with other foodstuffs, improved transport, the increased application of food technology and the truly 'mass' media have no doubt contributed to this trend.

Returning to breakfast, another area of change in recent years has been the growth in the inclusion of fruit or fruit juice. Warren (1958) reported just over $4 \%$ of adults consuming fruit or fruit juice at breakfast, these items being slightly more popular amongst women. The Kraft survey of 1978 , while finding a similar pattern of differences between the sexes, noted that $15 \%$ of women and $12 \%$ of men included fruit or fruit juice at this meal. This report also noted a regional variation with popularity higher in the south than the Midlands and north. A social class difference was also evident. Amongst the ABC groups $22 \%$ of women and $16 \%$ of men had fruit or fruit juice at breakfast compared with $10 \%$ of women and $6 \%$ of men among the CDE groups.

Since National Food Survey data show variations in fresh fruit consumption according to income level (see Fig. 4), it seems reasonable to suggest that price

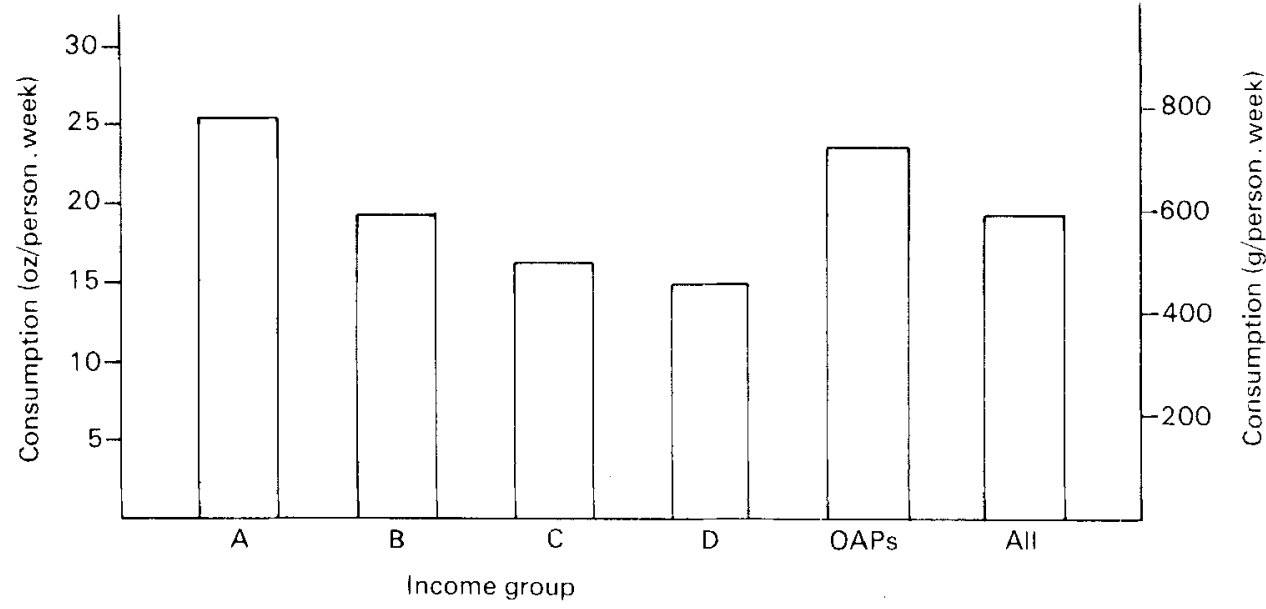

Fig. 4. Consumption of fresh fruit according to income group (Ministry of Agriculture, Fisheries and Food, I981). 


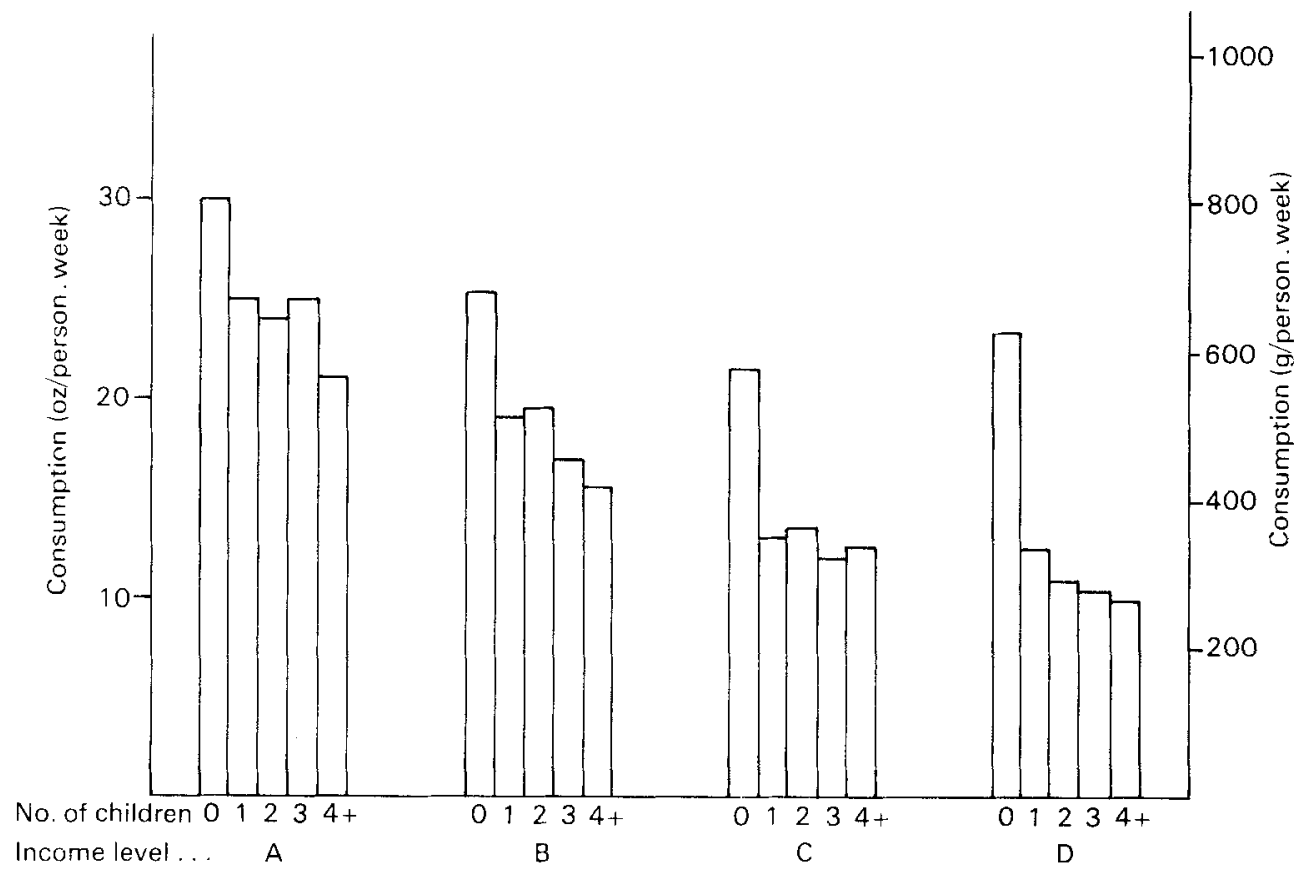

Fig. 5. Consumption of fresh fruit according to the number of children in a household (two adults) at each income level (Ministry of Agriculture, Fisheries and Food, 198I).

may play a role in determining fruit consumption. The fact that consumption declines with increasing number of children in the household at each income level (see Fig. 5) also tends to support this view, since finance must be stretched further under such circumstances. These patterns of family variation are certainly not new. The Rowett Research Institute survey (1937-39) found that the range in consumption of fresh fruit was very great, from $22.9 \mathrm{oz}\left(65_{5}^{\circ} \mathrm{g}\right) /$ head per week in families with one child to $6.6 \mathrm{oz}(\mathrm{I} 80 \mathrm{~g})$ in those with six or more. By 1955 the National Food Survey indicated that some levelling had taken place, the extreme values being $18.6(530 \mathrm{~g})$ and $7.0 \mathrm{oz}(200 \mathrm{~g})$. The values for 1979 were $2 \mathrm{I} \cdot 2 \mathrm{oz}$ $(600 \mathrm{~g})$ in households with one child and $\mathrm{I}_{4} \cdot 3 \mathrm{oz}(400 \mathrm{~g})$ where there were four or more children, suggesting that not only may the difference in consumption have been further reduced (although the values were not exactly comparable-four or more children with six or more children) but that the over-all level of consumption of fresh fruit has increased.

There is considerable regional variation in fruit eating patterns (see Fig. 6) also noted before the war by the Rowett Research Institute survey. This again may be in part a question of economics. Food generally is more expensive in Scotland than in England. The index of comparative prices (all foods) being 99.7 for England, 99.7 for Wales and 104. 5 for Scotland in 1979 (Ministry of Agriculture, Fisheries and Food, $198 \mathrm{I}$ ). Other regional information indicates considerable variation in the price of fruit, and if we consider the most widely consumed fruit in the 


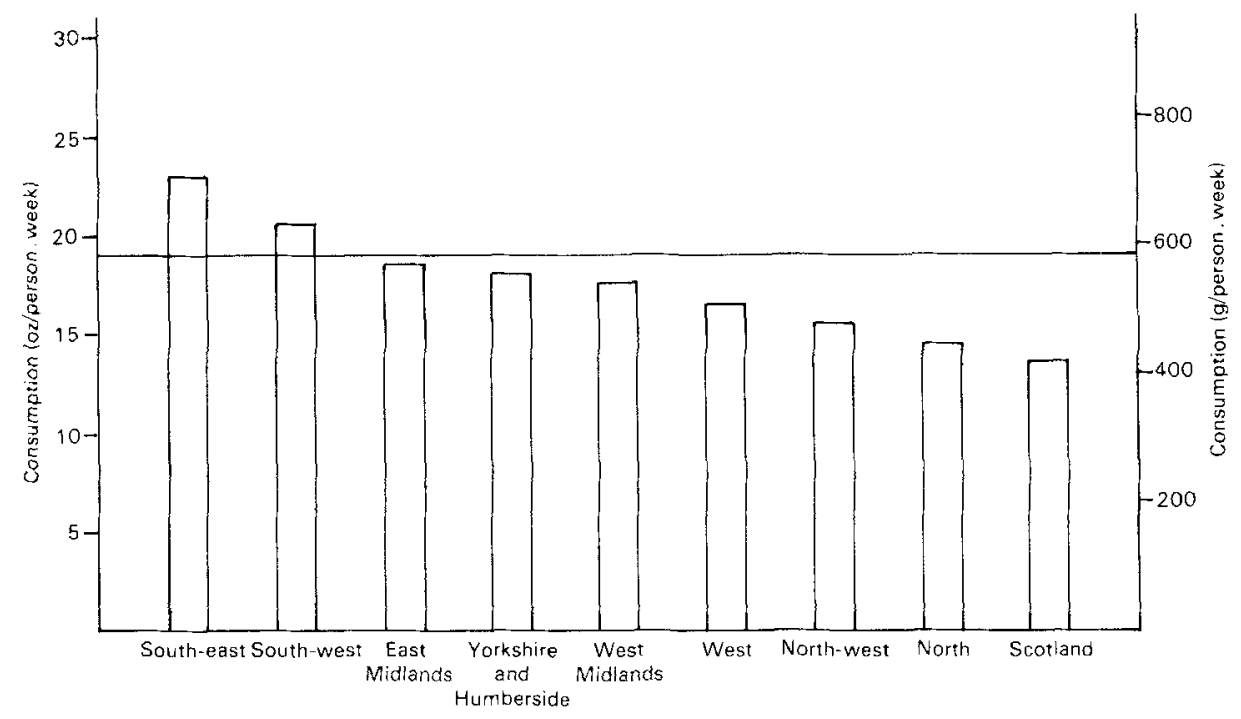

Fig. 6. Consumption of fresh fruit according to region (Ministry of Agriculture, Fisheries and Food, 1981). The horizontal rule shows the national average level of consumption.

UK--apples - the average price in September $198 \mathrm{I}$ ranged from $19.9 \mathrm{p} / \mathrm{lb}$ $(44 \mathrm{p} / \mathrm{kg})$ in the east Midlands to $24.7 \mathrm{p} / \mathrm{lb}(55 \mathrm{p} / \mathrm{kg})$ in the south-east and 26.0 $\mathrm{p} / \mathrm{lb}(57 \mathrm{p} / \mathrm{kg})$ in Scotland (British Broadcasting Corporation, survey data from 'Shopping Basket' radio programme, $198 \mathrm{r}$ ). Clearly in earlier times availability must have contributed in large part both to the price of fruit and the development of a fruit-eating tradition. References to an 'apulder-tun', apple tree enclosure or orchard, by the Anglo-Saxons suggests that apples were their commonest form of fruit and later the Norman conquest brought the introduction of new varieties which had been developed in France. Later, in the 13 th century, there are records indicating that cuttings of French varieties were purchased by the Earl of Lincoln (Wilson, I973). Climatic difficulties imposed limitations on the nature and extent of fruit growing. In I6th century Yorkshire there was no point in trying to grow the apricots, quinces or peaches which had become popular in southern England after their first earlier importation from warmer climes. Fruit was principally raised in the gardens of the gentry in the north. There were parts of the north-west where even apples and pears were hardly known among ordinary people before the 18 th century. In Scotland too, fruit growing was largely confined to castle and monastic gardens until the 17 th century. In the 18 th century fruit pies and tarts were enjoyed increasingly in the north of England. The development of the canal system allowed apples and plums to be carried there from Kentish and other southern orchards.

The introduction of more exotic fruits into Britain shows two patterns still familiar to us today - the overseas traveller who wants to eat the foods he has enjoyed abroad and the newcomer who longs for familiar fare. On one hand the 
first Englishmen to enjoy oranges and lemons were probably those who wintered with Richard Coeur de Lion in the groves around Jaffa, I I $\mathbf{I} \mathbf{I - 9 2}$, while there are also records of lemons, oranges and pomegranates being brought to this country in I 289 for Queen Eleanor - formerly a Princess of Castille.

The seafaring and colonial past of the country has played a part too. The pineapple, discovered in the New World by Spanish settlers, was also accepted by the English, the first example being brought to Britain in Cromwell's time. Bananas had been discovered in West Africa as early as the ${ }_{5} 5_{\text {th }}$ century, but it was via the Canaries and West Indies that they came to England. The first bunch of bananas arrived from Bermuda in 1633 . But bananas were far too perishable to form a regular item of trade, until the coming of steamships in the r 9 th century. As a final comment on breakfast, perhaps we should consider the accompanying beverage. At the present time it seems that tea is still the most popular drink at breakfast time (Kraft, 1978 ) being mentioned by ${ }_{5} \%$ women and $61 \%$ men, with its most loyal following in the Midlands. Only $30 \%$ of women and $23 \%$ of men drank coffee, with popularity being greater in the south. This represents quite a change in the last twenty or so years. Warren (1958) reported that $82 \%$ of men and $80 \%$ of women drank tea at this time of day, compared with $4 \%$ of both men and women who drank coffee. However, the regional pattern was similar, with tea drinking more common in the Midlands and north and coffee drinking more popular in the south with breakfast. Coffee drinking was least popular amongst the older age groups and those referred to as 'lower class' (in manual occupations, salesmen and low grade clerical staff, pensioners).

Individual travellers, such as Nathaniel Conopios whom John Evelyn saw drinking coffee in Balliol College in 1637 , first brought the custom to England. Oxford also provided the home of the first coffee house opened in $165^{\circ}$; a second followed in London two years later. Soon many such establishments were opened, popular in part because of their all male club-like atmosphere perpetuated from the Eastern coffee houses. Coffee remained expensive, for it was costly to import and was made liable to excise duty. In England the new drink soon spread to the homes of the gentry and continued to grow in popularity until the Georgian era, when it began to feel the competition from tea. It remained a drink of the gentry and middleclasses principally because of the high price which was maintained due to the difficulty of counterfeiting or adulterating the product.

In the 17 th century that other important drink, tea, arrived. The East India Company began bringing small amounts direct to England in $I 664$, at first via Malaya and subsequently directly from Amoy and Canton. Tea remained expensive, in part because of the excise duty charged. Despite the high cost the habit gathered momentum. Its success was ensured when the wife of Charles II encouraged tea drinking at court. The East India Company also started to import genuine China tea cups and tea pots, a bowl for sugar and a salver to hold all the items completed the set. Copper or silver urns were also introduced so that the hostess could brew and serve tea amongst her guests, a ceremony with considerable appeal. The expense of the tea added a further cachet to the person 
who offered it, a factor which in due course helped to spread tea drinking further down the social scale. With the development of Vauxhall and other tea gardens, which were open to servant girls as well as their mistresses, the habit spread still further. When possible, consumers would add both milk and sugar and the growth in tea drinking was largely responsible for the rising sugar consumption in Britain in the 18 th century. Although more tea was being drunk, the price, inflated by customs duties, kept the finest varieties in the luxury class. The pressure of demand, however, soon resulted in a variety of counterfeiting practices and adulteration. In 1784 the duty on tea was at last lowered and by the end of the century tea was well on its way to becoming the national drink of Britain or at least its southern half. For the labourer tea was considered a necessity. High food prices, enclosure and their general poverty had reduced them to a diet of bread, cheese and occasionally bacon. Through lack of fuel they had lost the art of making warm soups so tea became not simply the sole liquid to wash down their dry meals but also the only warm and comforting element in their diet.

Sir William Crawford in his surveys (1936-37) found that tea was still the almost universal breakfast drink in England amongst the 'lower' classes, $98.3 \%$ of whom drank tea as opposed to $88.6 \%$ of his social class $A$. Coffee drinking declined rapidly below social class $B$.

The stories of tea and coffee provide some interesting insights into patterns of changing food habits. Both coffee and tea had considerable social appeal, originally because of their expense and consequent exclusivity. However, in practical terms one product could build on this to meet the popular demand, tea, whereas the other, coffee, could not so that coffee remained in common usage amongst a social minority, at least until after the Second World War. No doubt the appearance of acceptable forms of instant coffee which could be made with convenience have made a considerable contribution to the more widespread use of coffee. There still remains a social distinction, however, between 'real' coffee made from beans and 'instant coffee'. Many advertisers have run successful campaigns on the basis of the association of a particular product with the 'affluent' classes, a technique not unknown to baby-milk manufacturers in developing countries. It certainly seems that many ideas about food and nutrition do 'filter down' and we may be seeing the same sort of phenomenon in relation to breast feeding in the UK. Similarly, some newcomers may attach prestige to doing things in 'the British way'.

Though breakfast is not so widely consumed as it was in $195^{8}$ when Warren reported $92 \%$ of the population eating it, there is no doubt that breakfast still exists, albeit as a less important meal. The foods being included provide some interesting points of reference in considering the underlying factors and trends in British dietary habits.

\section{The mid-day meal}

Clearly the mid-day meal is a different affair on weekdays compared with the weekend. For one reason in particular, it is more likely to be a family meal at the weekend. A survey by Kraft ( 1978 ) reported that $80 \%$ of men and $73 \%$ of women 
claimed that the entire family sat down together for a meal everyday, while $20 \%$ of women and $12 \%$ of men said this happened only at the weekend. During the week, a meal which the whole family shares is far more likely to be in the evening. Family meals seem to occur more frequently in the north and are more likely to occur at the weekends in the Midlands and south. One set of contributing factors is made up of simple environmental ones, namely whether the husband works close enough to home to make it possible to return to lunch; similarly whether the wife is available at mid-day or working. In the north there is a tendency for work and home to be closer, whereas in commuting areas such as the south and south-east, fathers may not only be away at lunch-time but return in the evening after young children have gone to bed during the week. If the family can eat together at mid-day it is more likely that this will be a substantial meal, perhaps with a high tea being served later. Where lunch has been a snack for the housewife or eaten away from home there is much more likelihood that an evening meal, or dinner, will be the most important meal of the day. Eating a meal together is a symbolically important act in many cultures and disruption in family meal routine may be rather more disturbing to individuals than any nutritional considerations would seem to warrant. For this reason the differences in meal patterns between the indigenous population and Asians, noted by Hunt ( 1977 ), are valuable in reminding us of the sort of adjustment that newcomers may be called upon to make (see Table I). These differences also indicate a change in lifestyle, e.g. the traditional pattern of a family meal at lunchtime being no longer possible in the UK.

It seems likely that people are prepared to make modifications first to those meals which are least important (Fox \& Yang, 1979). Hence the widespread adoption of breakfast cereals amongst many ethnic groups in a variety of alien locations (Wenkam \& Wolff, 1970; Bavly, 1966). The degree of importance attached to the mid-day meal may therefore crucially affect peoples' willingness to accept new foods if exposed to them at this meal. Similarly, if we observe consumption of particular items during the most important meal it may give a strong clue as to the degree of acceptance of a non-traditional food.

\section{Table 1. Meals in Uganda and Britain*}

\begin{tabular}{|c|c|c|c|c|}
\hline & \multicolumn{2}{|c|}{ Lunch } & \multicolumn{2}{|c|}{ Supper } \\
\hline & Uganda & Britain & Uganda & Britain \\
\hline Largest meal & 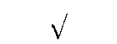 & $x$ & $x$ & $\sqrt{ }$ \\
\hline Hot food used & $\sqrt{ }$ & $x$ & $\sqrt{ }$ & $\sqrt{ }$ \\
\hline Highly structured & $\sqrt{ }$ & $x$ & $x$ & $\sqrt{ }$ \\
\hline Mostly traditional foods & $\sqrt{ }$ & $x$ & $\sqrt{ }$ & $\sqrt{ }$ \\
\hline Rice and wheat & $\sqrt{ }$ & $x$ & $\sqrt{ }$ & $\checkmark$ \\
\hline Little use of leftovers & $\sqrt{ }$ & $x$ & $x$ & $\sqrt{ }$ \\
\hline Few convenience foods & $\sqrt{ }$ & $x$ & $x$ & $\sqrt{ }$ \\
\hline Few British foods & V & $x$ & $\sqrt{ }$ & $\sqrt{ }$ \\
\hline
\end{tabular}




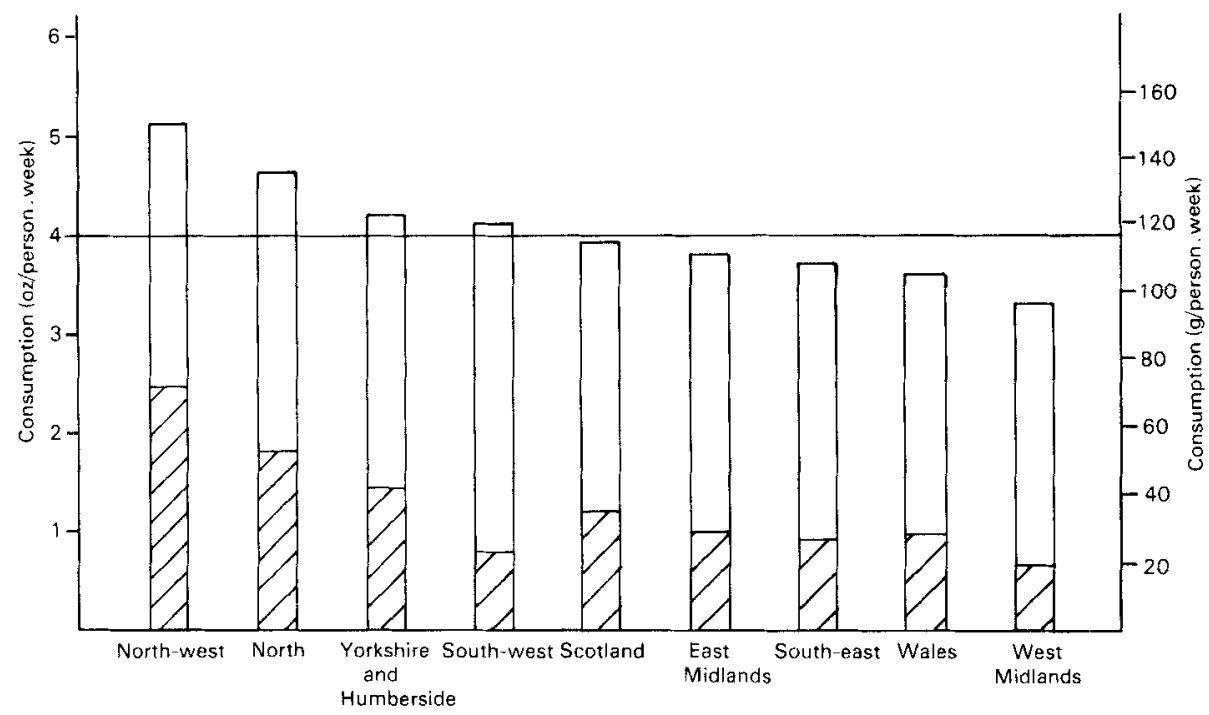

Fig. 7. Consumption of (勿) buns, and ( $\square$ ) cakes and pastries according to region (Ministry of Agriculture, Fisheries and Food, $198 \mathrm{r}$ ). The horizontal rule shows the national average level of consumption.

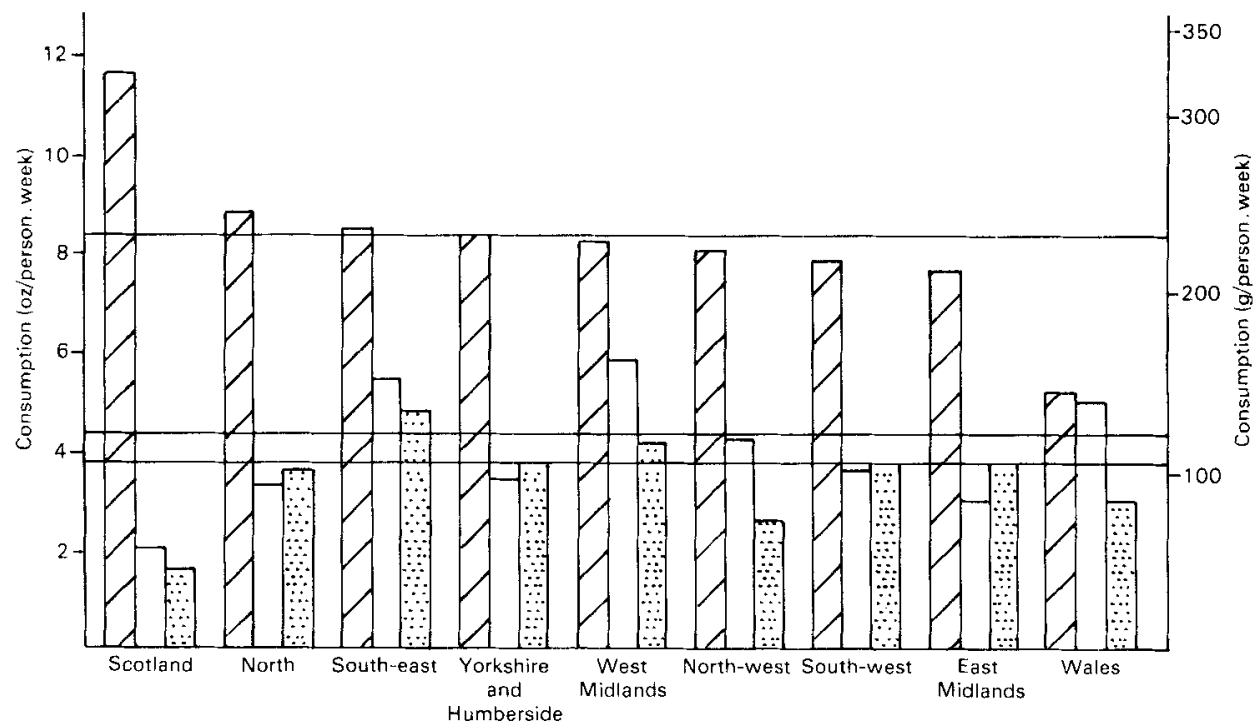

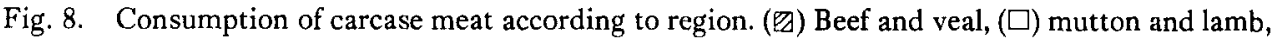

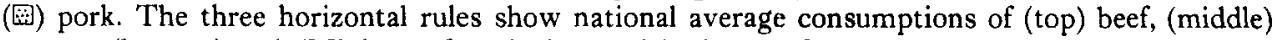
mutton, (bottom) pork (Ministry of Agriculture, Fisheries and food, 198r).

\section{Evening meal}

The regional variation in the consumption of a 'high tea' type meal tends to be supported when we look at data concerning consumption of cakes, pastries, buns and scones (see Fig. 7) which usually form a feature of this meal. Where the 
evening meal is the most important meal of the day a main dish of meat or fish is most frequently included. This seems to be the hallmark of a 'proper meal' as opposed to a snack, whether at mid-day or in the evening. For this reason perhaps, $46 \%$ of women (Kraft, 1978 ) agreed that their husbands would complain if they served them a meal without meat or fish in it. When men were asked if they would accept such a meal, rejection was strongest in the Midlands and amongst men in the $\mathrm{C}_{2} \mathrm{DE}$ social groups. There is a considerable variation throughout the country in both the types of meat consumed and the cuts preferred. A first glance at the National Food Survey data shows differences between consumption of the three carcase meats, beef and veal, lamb and pork (see Fig. 8). Beef and veal consumption is above the average in Scotland, the north and south-east, but below average everywhere else, particularly in Wales. Mutton and lamb consumption is substantially below average in Scotland and the north of England but above average in Wales. Pork consumption, below average in Scotland, is substantially higher than average in the south-east and west Midlands.

Freeman ( 1980 ) has examined unpublished data concerning meat cuts and meat products from the National Food Survey (1972-77) with interesting results (see Table 2). The consumption data, originally in the form of weight of meat/person per week, were transformed onto an 'adult equivalent basis' to remove any regional variation in consumption resulting from differences in the age and sex structure of the regional population. In addition, further adjustments were made to the data to allow for fluctuations in regional consumption patterns because of regional income variations and consumer responses to regional prices. The differences in regional patterns of consumption are much more marked for cuts of beef than for other carcase meats. While the north consumes an average amount of total beef, the consumption of joints and mince is above average while that of steak is below. On the other hand, in the west Midlands, another region of average consumption, the consumption of joints is above average while steak and mince are below.

With regard to lamb and pork the pattern of consumption of the various cuts is fairly consistent with the pattern of total consumption. This suggests that consumers either like or dislike this type of meat irrespective of cut. Wide variations are also seen with non-carcase meats. Ready-cooked pies and sausage rolls appear to have a north-south division as do canned meats, which may be related to their use in some parts as the constituents of 'high teas'. Although both Scotland and the south-east are above average consumers of frozen convenience meats and sausage there is further variation in that this position is largely due in Scotland to sausages, especially beef ones, while the south-east is a much higher consumer of frozen convenience meats than Scotland.

Clearly beef is still the most popular meat in the UK, a preference which had already emerged by the mid- $I$ th century when drovers were taking cattle from Wales to Gloucester and beyond. In the I8th century A. and D. Driver (Burnett, I 968 ) record that farm labourers 'living in' with their employers generally fed on pork and pudding, 'except on Sundays when a joint of meat is sometimes allowed'. It appears that well-fed labourers did not regard the pig as being in the same class 


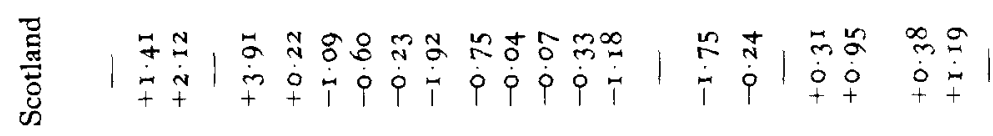

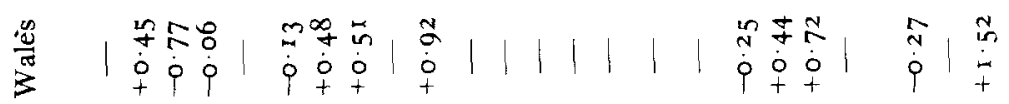

若

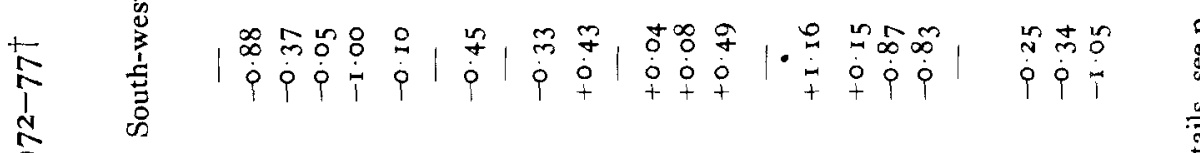

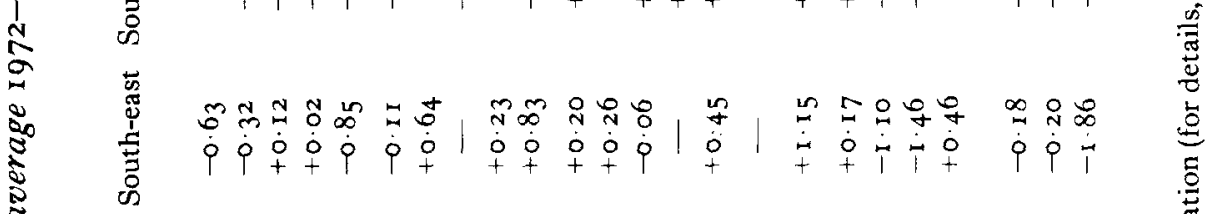

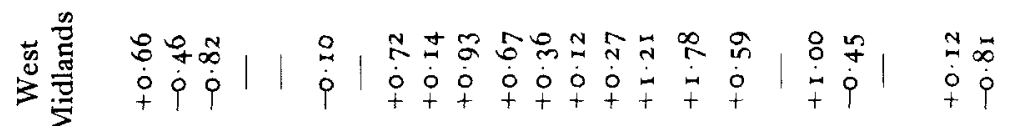

若

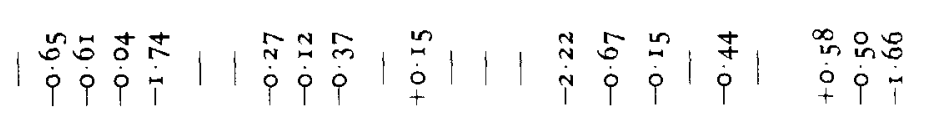

ㄷํㅇำ

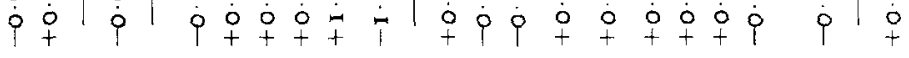

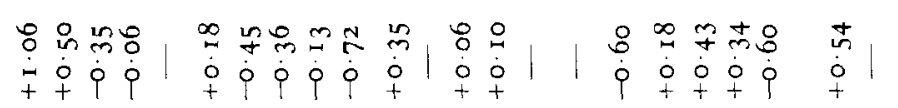

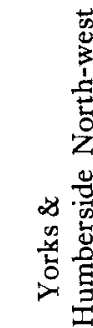

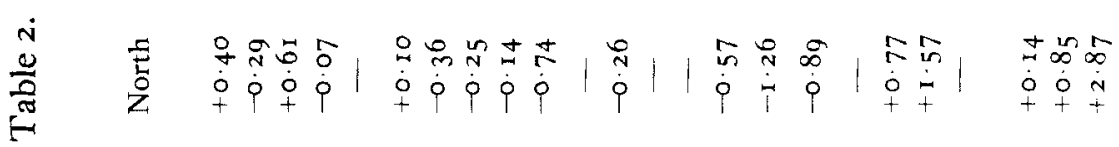

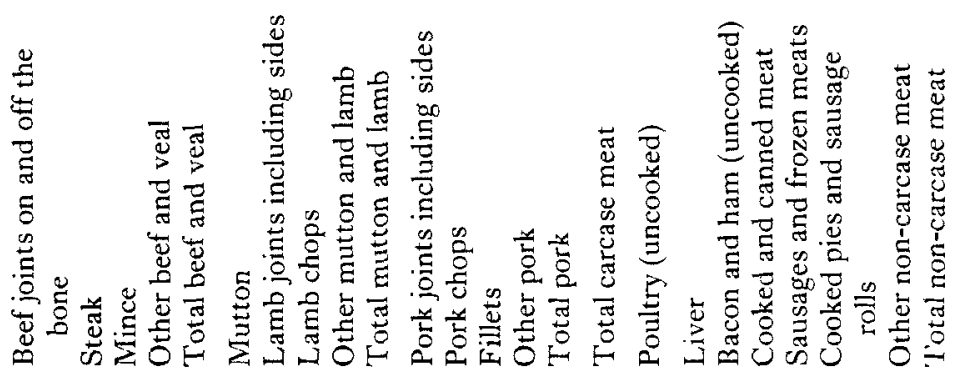


as beef. However, the hard-pressed agricultural labourer of the I 9 th century was no doubt pleased to see even pork and Dr Edward Smith in his 1862-63 survey (Barker et al. 1970) reported that pickled pork was almost the only meat available in Dorset, Somerset and the eastern counties. In more recent years, production and price factors have markedly increased the consumption of chicken as a cheap meat since the war. The National Food Survey indicates that, between $195^{6}$ and 1965 consumption of poultry rose steadily from $0.59 \mathrm{oz}(\mathrm{10} \mathrm{g})$ to $3.3^{8} \mathrm{oz}(95 \mathrm{~g}) /$ head per week. Following a change in classification the next five years, 1966 to 1970 , saw consumption of broiler chicken increase from $2.66 \mathrm{oz}(75 \mathrm{~g})$ to $3.5 \mathrm{I} \mathrm{oz} \mathrm{(100} \mathrm{g)/head}$ per week. Uncooked broiler chicken (including frozen) grew again to $3.76 \mathrm{oz}$ ( $106 \mathrm{~g}$ ) in 1975 and had reached the value of $4.31 \mathrm{oz}(\mathrm{I} 22 \mathrm{~g}) /$ person per week in 1979. Oughton \& Baron ( 1980 ) trace the increased demand in the north-west to developments between 1870 and 1920 . Pressures on space in this industrialized area led the new urban dwellers to raise poultry rather than the more traditional pig, which persisted elsewhere in the north. Building upon this expertise, with the fall in cereal prices after $192 \mathrm{I}$, poultry production expanded rapidly on a commercial basis.

Although consumer surveys tend to suggest that while chicken is held to be versatile and economical it is not thought of as a particularly nourishing meat. Economics clearly play an important role in determining meat consumption. Baron \& Eagle (I98I) report that $28 \%$ of respondents had reduced the amount of meat purchased in the last two years because of the cost. It would seem that local habits represent a combination of traditional usage, partly based on varying agricultural history and economic factors. The relationship is not a directly price-related one, since beef, as with other foodstuffs, again tends to be relatively highly priced in the north and Scotland.

Traditionally most meat dishes are combined with vegetables and variations in the consumption of these are along similar lines to fruit, highest in the south-east and highest income group, lowest in Scotland and the low income group, reflecting in part historical considerations of production and transport.

In considering consumption of frozen vegetables we find that variation appears to be along similar regional lines. However, a more recent impinging factor may be freezer ownership, since not only is consumption of frozen vegetables higher among freezer owners, but there is also a geographical variation in ownership, being highest in London and the south $(52 \%)$ and lowest in Scotland $(27 \%)$ at the end of 1979 (Birds Eye, I980).

The other major accompaniment to meat and vegetables in some form is potato. Although there are regional and income level variations in consumption (see Figs. 9 and 10 ) it continues to be an important starchy staple food in Britain. It was not always so popular. Burton (1948) describes the factors which lay behind its rapid growth in popularity in Ireland compared with the apathy or hostility which greeted its arrival in 16 th century England. At that time England, with its population of approximately 4.5 millions, was not only self-sufficient in wheat but raised a surplus for export. Since Wales was also a self-supporting country of small 


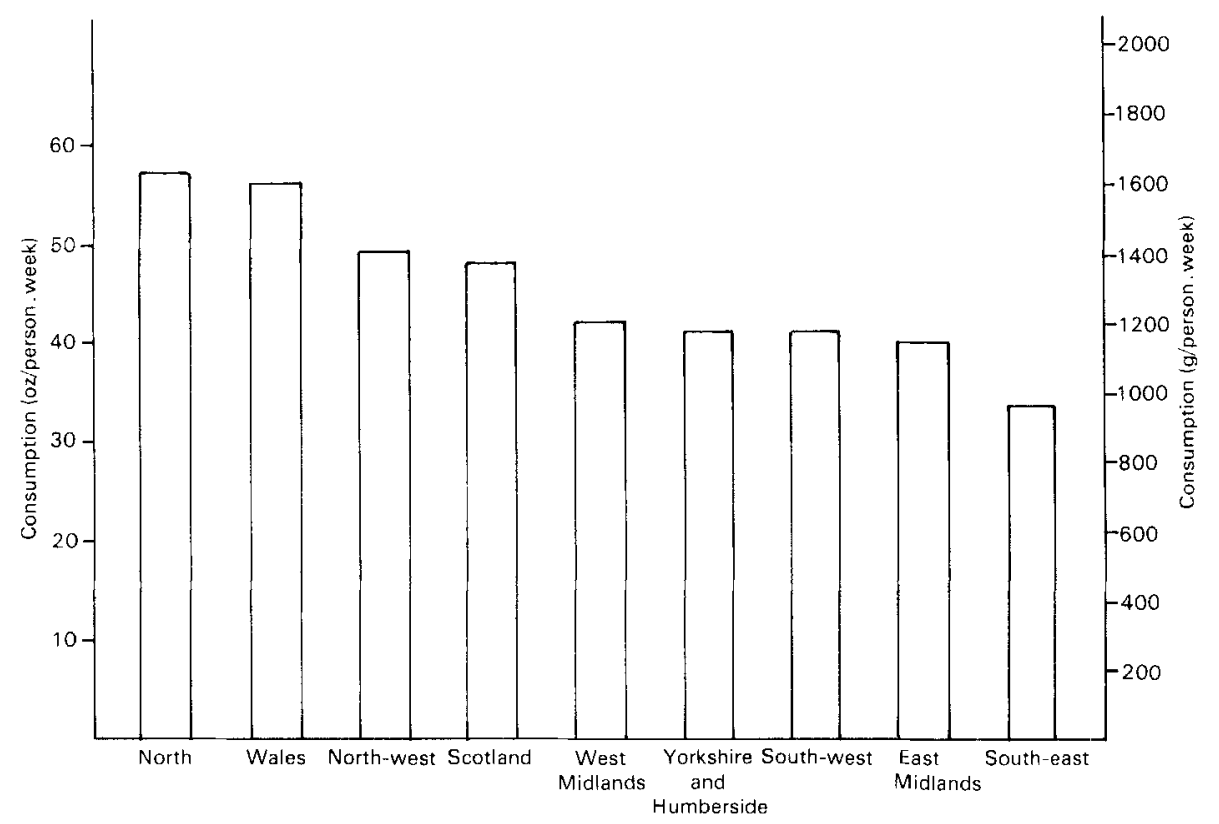

Fig. 9. Consumption of fresh potatoes according to region (Ministry of Agriculture, Fisheries and Food, 1981).

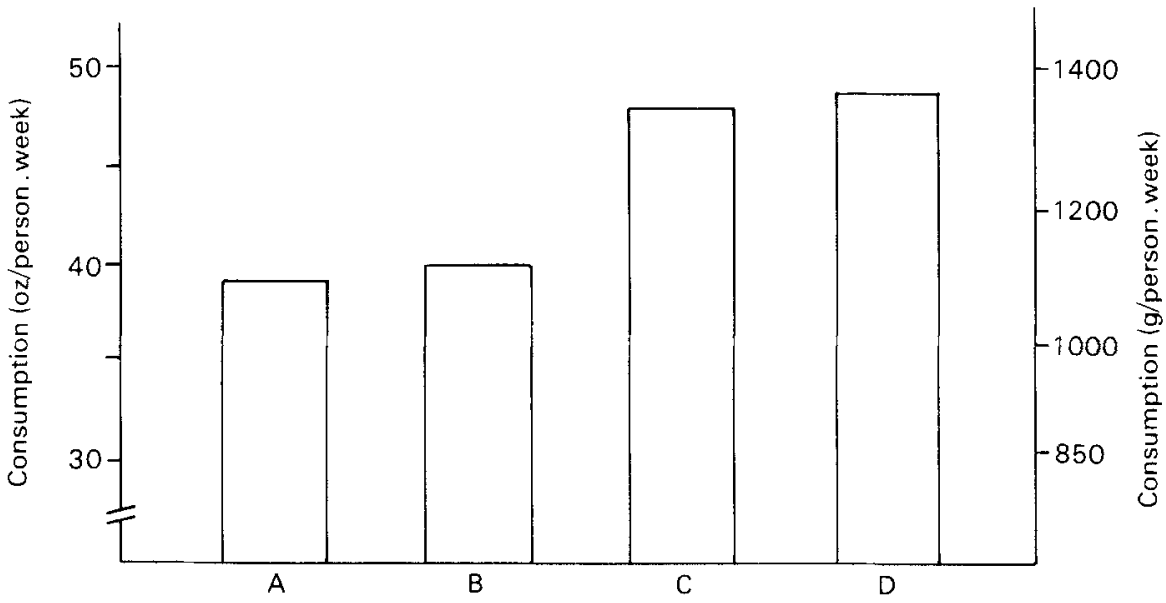

Fig. ro. Consumption of fresh potatoes according to income group (Ministry of Agriculture, Fisheries and Food, i98r).

farms, there was no incentive to cultivate the potato in either locality. The latter half of the 16 th century in Ireland presented quite a difference picture, with an almost perpetual state of minor warfare which occasionally flared up into open rebellion against the English rulers. The peasants as in all such situations were the chief sufferers, having their cattle driven off or slaughtered by one side or the other, and their land and crops ravaged by rival troops. The extension of the policy 
of granting land to English settlers put further pressure on the peasants until open rebellion broke out in $\mathrm{I} 64 \mathrm{I}$. This was finally put down with considerable severity by Cromwell ro years later in I $_{5} \mathrm{I}$. During this period the Irish had come to rely more and more upon the potato. Here was a crop which could be grown safely underground and dug up as required. In the following century, conditions if anything grew worse and in many parts of the country the potato became practically the sole food of the poorer people. In 1870 Young (Burton, I948) recorded that a barrel of potatoes containing $280 \mathrm{lb} \mathrm{(127} \mathrm{kg)} \mathrm{would} \mathrm{last} \mathrm{a} \mathrm{family} \mathrm{of}$ five persons for a week, indicating an average consumption of $8 \mathrm{lb}(3.6 \mathrm{~kg}) /$ person per d. This complete dependence on one crop paved the way inevitably for the failure of the harvest due to blight and subsequent famine in 1846 , resulting in mass emigration from the country in subsequent years.

Potatoes were probably introduced from Ireland into Scotland during the last quarter of the $17^{\text {th }}$ century, but their use did not become immediately widespread, the tradition of open field farming and relative social stability reducing its advantages. However, the provision of capital by industrial development in the Lowland during the latter half of the 18 th century made enclosure and drainage of land a viable proposition, which together with the high price of grain and increase in population favoured the cultivation of potatoes. The 18 th century also saw the condition of the Highlanders reduced to a level almost equal in misery to the Irish, which consequently rendered the potato an attractive crop and prevented many from starving. The 'Highland clearances' (in contrast to the subletting of small plots as in Ireland) resulted in many emigrating to America. This led to depopulation as opposed to the rapid rise in population which occurred in Ireland. Consequently, a potato-ridden economy as a means of supporting a large population did not arise in Scotland. Ireland, in fact, acted as a focus for the spread of the cultivation of the potato as a common article of food. As a result it spread to those parts of England which were most in contact with Ireland. Lancashire was the main point of contact and Holt in $\mathbf{I} 795$ refers to this county as 'the first county in this country in which the potato was grown'. The spread of cultivation was not very rapid until two developments occurred: firstly, the enclosure of land, providing suitable farming conditions; secondly, the Industrial Revolution, associated with an increase in population so that grain supplies were no longer adequate. This concentration of increased population also occurred in the north where production was not, at the best of times, very high. Development of industry also encouraged some of the impoverished Irish to settle in England. Holt wrote in 1795: "Above 5000 Irish were settled in Manchester in 1787, and I am told that number was afterwards doubled'. The arrival of this workforce used to a potato diet may itself have provided a stimulus to the cultivation of potatoes.

It was, in part, this rapid industrial expansion which provided employment for displaced agricultural workers preventing the widespread deprivation seen in Ireland, where the only alternative was emigration. Growth in more efficient farming methods and the repeal of the Corn Laws also militated against the development of the monoculture which had such disastrous results in Ireland. 
Clearly a variety of social factors have affected the spread of potato cultivation, a history which can still be seen to some extent in current patterns of consumption.

\section{Eating between meals}

Apart from the main meals of the day, there is a considerable amount of eating in between. Respondents to a Health Education Council survey (1979) were most likely to take a snack after the main evening meal $(46 \%)$, while $30 \%$ eat something during the afternoon and $28 \%$ had a snack between breakfast and lunch. This represents a reduction from the position in 1958 reported by Warren, $41 \%$ of men and $53 \%$ of women usually had 'elevenses'. There appears to be a regional and social class variation according to the 1979 data, with snacking generally being slightly more common in the north and amongst the D,E social groups. Consumption of sweet biscuits on these occasions seems to be more popular in the south, while as might be expected, fruit eating also follows this pattern. Eating sandwiches as a snack is encountered more frequently in the north. Chocolate consumption is more popular amongst younger groups and $\mathrm{ABC}$ respondents. It seems likely that availability may play an important role in what is consumed at these times in addition to taste and other preferences. Such availability may in turn be related to regional variations in employment patterns.

\section{Other aspects of eating habits in the UK}

To understand a society's response to food it is essential to appreciate some of the non-nutritional uses to which food can be put. It is in this area, which is frequently not articulated, that the newcomer may have particular problems. The use of confectionery as a reward, deeply embedded in our culture, may not present many problems but the status hierarchy of foods and the use of those items to indicate social distance may present inter-cultural difficulties. Food in all societies plays a major role in initiating and maintaining personal relationships. The interpretation of this general phenomenon in the UK has increasingly been associated with eating outside the home. Catering has been a mushrooming business since the Second World War. Pubs have increasingly returned to their original function of selling food, rather than just a packet of crisps with the drink. The fish and chip shop and chop house have been joined by a variety of 'ethnic' restaurants of which the most popular serve Indian or Chinese dishes. In a recent survey (J. E. Thomas, unpublished results) there were 5.5 thousand establishments serving Chinese food in England, Scotland and Wales. To some extent these outlets occupied an 'ecological niche' in terms of price and quick service, at the same time appealing to a new interest in 'exotic' foods though often the range of dishes offered and their production have been adapted to British tastes. Similarly 'curry', a product whose popularity in England stemmed from the experience of returning colonials has grown to mass popularity. For domestic consumption it represents an interesting way to use up left-over cold meats and when eating out, it again usually represents good value for money. Eating out may present problems, however, for newcomers. They may be unused to situations where men and 
women eat together and, of course, under these circumstances one does not have knowledge of how food is prepared and the food items themselves may not always be clearly recognizable. These difficulties may apply particularly to children in the case of school meals.

Popular understanding of the relationship between diet and health may directly affect the choice of foods, and cultural differences in this area may make for difficulties in a variety of contexts. As a small example, $65 \%$ of people in the north in a recent survey by Baron \& Eagle ( $198 \mathrm{I}$ ) believed that meat is necessary for a good diet. Clearly the vegetarian in this setting may experience areas of conflict.

A major non-nutritional use of food is for the expression of socio-religious ideas, and the reinforcement of group of identity. Again, a newcomer's approach to food in this context may differ widely from that of the host community. The most prolonged dietary practice associated with religion in this country has been the consumption of fish on Fridays, which in many areas has been absorbed as a traditional habit long after the breakaway of the Church of England and despite the release from this practice of Roman Catholics. Though it should be said that throughout history the pursuance of this outwardly religious practice has been manipulated from time to time for political and economic reasons, to promote the construction of boats in the Elizabethan era for example.

Foods are often used to cope with psychological stress, and for many newcomers the eating of traditional foods may provide a valuable source of relief in a situation beset with stresses. Clearly then, the foods chosen in this context will be very different from those a longer term inhabitant of the UK would consume at such times. However, the foods that the latter might choose will be affected by income, social background, regional origin, sex and age--a tradition of eating habits shaped by the history of the country, including generations of newcomers with new ideas about food.

\section{REFERENCES}

Anderson, E. N. \& Anderson, M. L. (1969). Ethnos 1, 4, Io7.

Baines, A. H. J., Hollingsworth, D. \& Leitch, I. (1963). Nut. Abstr. Rev. 33, 3, 23.

Barker, T. C., Oddy, D. J. \& Yudkin, J. (1970). The Dietary Surveys of Dr Edward Smith, I 862-3. Department of Nutrition, Queen Elizabeth College. Occasional Paper No. I.

Baron, P. J. \& Eagle, R. ( $198 \mathrm{I})$. Consumer attitudes to different cuts and types of meat. Department Agricultural Marketing, University of Newcastle upon Tyne, Report no. 2.

Bavly, S. (1966). F. Am. Diet. Ass. 48, 488.

Birds Eye ( 980$)$. Business Report. Birds Eye.

Burnett, J. (I 968). Plenty and Want. London: Pelican.

Burton, W. G. (1948). The Potato. London: Chapman and Hall.

Crawford, W. \& Bradley, H. (1937). The People's Food. London: William Heinneman.

Fox, H. M. \& Yang, G. I. P. (I979). F. Am. Diet, Ass. 75, 420.

Freeman, S. (1980). Meat Trends September, I.

Health Education Council (1979). Evaluation of the 'Better Health' campaign. London: Health Education Council.

Hunt, S. ( 1977 ). Adaptation and Nutritional Application of Food Habits among Ugandan Asians Settling in Britain. PhD thesis. Queen Elizabeth College, University of London.

Kraft (1978). A Survey of Attitudes to Food and Health, Part I. Cheltenham Glos.: Kraft Foods Ltd. 
MAFF (1981). Household Food Consumption and Expenditure, 1979. London: HM Stationery Office.

Oughton, E. \& Baron, R. J. (1980). Regional Consumption Patterns of Meat in the UK. Oxford Agrarian Studies IX, I I 5 .

Warren, G. C. (1958). The Foods We Eat. London: Cassell.

Wenkam, N. S. \& Wolff, R. J. (I 970). F. Am. Diet. Ass. 57, 29.

Wilson, A. (1973). Food and Drink in Britain. London: Constable Co. 